\title{
26 Sex in the Village
}

\section{Maki Hirayama}

At the Rio Olympics, 350,000 condoms were distributed for free. There is an unwritten rule that the athletes can never speak about romance and affairs that occur inside the Olympic Village. Not a few players are said to sexually enjoy Coubertin's ideal of the "garden of youth of the world." For Japanese condom companies, the Olympics is a great opportunity to promote their high-quality "Made in Japan" products to the overseas market. Japan's two top condom companies, Okamoto and Sagami, have been competing to be the supplier to the Olympic Village. They have successfully developed 0.01 $\mathrm{mm}$ condoms, the thinnest worldwide. Okamoto products use natural rubber, while Sagami uses polyurethane, which is notable for being "rubber allergyfree" and having no rubber odor.

Why did the development of durable and thin condoms advance this far in Japan? The advanced technology of the manufacturing industry is one reason, but specific tendencies in Japanese contraceptive usage are the main reason. Japan was the last member of the United Nations to approve contraceptive pills in 1999, and even today they represent only a small percentage of contraceptives used. Other more recent methods such as implants, patches, and injections have not been approved, with critics claiming that contraceptive methods that women can use by themselves would "disturb the social order." As a result, condom use accounts for more than $80 \%$ of contraception, and the demand for high-quality condoms is very high in Japan.

Nonetheless, over the past 30 years there has been a continuous reduction in the domestic consumption of condoms, from 600-700 million per year in the early 1990s to 200-300 million in the late 2010s. This has been triggered by a range of factors such as the aging of the population, population decline, as well as supposedly overall lower rates of sexual activity in the population. Thus, Japanese condom makers are keen on expanding their market to international consumers. 